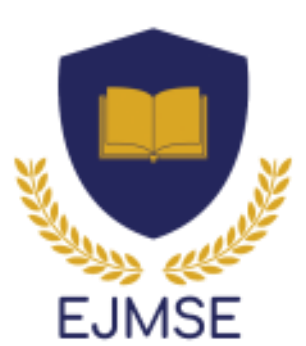

European Journal of Mathematics and Science Education

Volume 1, Issue 2, 67 - 80.

ISSN: 2694-2003

https://www.ejmse.com/

\title{
Science Teachers' Conceptions of Atomic Models
}

\author{
Jeff Wiener*iD \\ CERN, SWITZERLAND
}

Received: July 9, 2020 - Revised: November 11, 2020 • Accepted: December 13, 2020

\begin{abstract}
This article presents an international study that documented the conceptions of atomic models held by 1062 in-service high school science teachers from 58 countries. First, a previous study on pre-service science teachers' conceptions of atomic models was successfully replicated as a pilot study with an international sample of in-service science teachers. Teachers' conceptions were investigated by analysing their drawings of atomic models. Based on these results, a multiple-choice questionnaire was developed for the main study. This questionnaire collected data on teachers' conceptions of atomic models, teachers' knowledge about their students' conceptions of atomic models, and teachers' use of atomic models in the classroom. The results show that the teachers' conceptions of atomic models are almost evenly distributed over six different atomic models. These models are the Bohr model, the Rutherford model, the probability model, the orbital model, the probability orbit model, and the wave model. The vast majority of teachers assume that their students' conceptions are centred on two historical atomic models, namely the Bohr model and the Rutherford model. Furthermore, the majority of teachers prefer to use historical atomic models over modern atomic models in the classroom. However, the findings also highlight that the use of modern atomic models in the classroom is positively correlated with growing teaching experience, and that teachers' conceptions of atomic models and their knowledge of students' conceptions of atomic models significantly influence teachers' classroom practice.
\end{abstract}

Keywords: Teachers' conceptions, atomic model, in-service science teachers.

To cite this article: Wiener, J. (2020). Science teachers' conceptions of atomic models. European Journal of Mathematics and Science Education, 1(2), 67-80. https://doi.org/10.12973/ejmse.1.2.67

\section{Introduction}

More than 2500 years ago, Leucippus and Democritus introduced the concept of atoms as indivisible units that make up ordinary matter. Their original model of atoms remained virtually untouched until the end of the 19th century, when the discovery of the electron by Thomson (1897) spearheaded the establishment of the field of elementary particle physics. Indeed, finding the first subatomic particle drastically changed the description of the natural world and, based on new advancements in the field of particle physics, the ancient model of atoms was continuously improved and refined. Today, it is fair to say that the atomic theory is one of the essential notions of our current scientific knowledge. Or, as Richard Feynman put it so eloquently at the beginning of his famous lectures:

All things are made of atoms-little particles that move around in perpetual motion, attracting each other when they are a little distance apart, but repelling upon being squeezed into one another. In that one sentence, you will see, there is an enormous amount of information about the world, if just a little imagination and thinking are applied

(Feynman et al., 2010, p. 2).

\section{Literature Review}

The particulate nature of matter is a fundamental topic in science, and in particular in science education (Park \& Light, 2009; Snir et al., 2003; Treagust et al., 2010; Vikström, 2014). However, what Richard Feynman envisaged as 'a little imagination and thinking' turns out to be a tremendous challenge in the classroom. Indeed, studies of students' conceptions about the particulate nature of matter have repeatedly shown that middle and high school students have significant difficulties in establishing an adequate understanding of particle models (Adbo \& Taber, 2009; Griffiths \& Preston, 1992; Harrison \& Treagust, 1996; Samarapungavan et al., 2017). Moreover, when it comes to students'

\footnotetext{
* Correspondence:

Jeff Wiener, CERN, Esplanade des Particules 1, 1211 Geneva 23, Switzerland. $₫$ jeff.wiener@cern.ch
} 
conceptions about particle models, vast discrepancies have been documented in their degree of coherence (Gómez et al., 2006; Wiser \& Smith, 2008), and research suggests a long-term spiral approach to be best suited for the teaching of the particulate nature of matter (Margel et al., 2008).

Specifically, due to the abstract nature of atomic models, such a spiral approach can enable educators to repeatedly emphasise model-building in science, which is considered to be a key process in the development of scientific knowledge (Gilbert, 2004; Hestenes, 1987). Here, the historical approach has received considerable attention in the field of science education research as a viable long-term approach to showcase the atomic hypothesis (Harrison \& Treagust, 2002; Justi \& Gilbert, 2000; Rodríguez \& Niaz, 2004). This educational strategy follows the historical development of atomic models, starting with ancient Greek philosophical atomism and leading to the description of a state-of-the-art atomic model. One advantage of this approach is that it enables students to follow in the footsteps of philosophers and scientists and thus gain knowledge both about the particulate nature of matter and the process of scientific advancements. For this, however, it is indispensable for educators to take students' conceptions into account and to enable them to construct their knowledge individually (Duit \& Treagust, 2003). Moreover, when following the historical approach, teachers have to avoid frequently mixing the use of different atomic models as this can lead to confusion among students (Eilks, 2015). Furthermore, Gunnarsson et al. (2018) highlight that teachers' knowledge of different atomic models and the relationship between them is vital for a successful introduction of the particulate nature of matter in the classroom.

These findings corroborate the fact that in all current working conceptualisations of Shulman's pedagogical content knowledge (PCK), teachers' knowledge of learners and their knowledge of instructional strategies are listed as distinctive dimensions (Park \& Oliver, 2008; Wiener et al., 2018). Moreover, they highlight the notion that teachers are one of the essential factors in the science classroom and that their values and beliefs play a crucial role in the educational process (Anderson \& Helms, 2001). Indeed, there is a long history of research into the construct of teachers' beliefs and how they influence teachers' practice (Fives \& Buehl, 2012; Pajares, 1992). However, the construct is widely considered to be 'messy' and in the literature, the terms 'teachers' beliefs' and 'teachers' conceptions' are used interchangeably (Barnes et al., 2017). Hence, for clarity, in this article the term 'teachers' conceptions' is exclusively used, intending to reflect "a more general mental structure, encompassing beliefs, meanings, concepts, propositions, rules, mental images, preferences, and the like" (Thompson, 1992, p. 130).

However, when looking at the literature, little is known about teachers' conceptions of atomic models. Specifically, while students' conceptions of the particulate nature of matter have received ever-increasing attention from the science education research community, only a few studies investigating teachers' conceptions of atomic models have been published. Furthermore, most of these studies focused on conceptions of pre-service teachers from one country and only a few studies were conducted with in-service teachers.

For instance, Jong et al. (2005) conducted a PCK study in the context of a one-year postgraduate teacher education programme with a group of 12 Dutch pre-service teachers to investigate their use of particle models. They reported that already at the beginning of the study, all pre-service teachers were able to describe specific learning difficulties related to the particulate nature of matter. In addition, their findings showed that all pre-service teachers acknowledged the importance of particle models throughout the programme. In contrast, Berqvist et al. (2016) conducted an exploratory PCK study with 10 Swedish in-service teachers to investigate their use of different representations when teaching chemical bonding models. Their findings showed that the in-service teachers were generally unaware of how their use of representations influenced their students' understanding. Furthermore, they were also unable to specify students' potential difficulties concerning chemical bonding models. Another prominent example is the study by Kiray (2016), who explored teachers' conceptions of atomic models by using the drawing method. A total of 142 Turkish pre-service teachers were asked to draw an atom on a blank sheet of paper. Here, Bohr's atomic model turned out to be the clear favourite, as it was drawn by half of the group. In contrast, only a few participants drew modern atomic models, and the findings indicated that the pre-service teachers had significant difficulties in making sense of the probabilistic nature of atomic models.

In summary, while a few studies have investigated teachers' conceptions about atomic models and dimensions of their associated PCK, several questions remained. For instance, the extent to which documented conceptions held by preservice teachers are suited to represent conceptions held by in-service teachers had not yet been established. Indeed, following the argument of Hashweh (2005), who describes PCK as a repertoire of pedagogical tools that teachers acquire over time through repeatedly teaching a particular topic, it is quite likely that teachers' conceptions develop and ideally improve over time spent in the classroom. Hence, dedicated research on documenting conceptions held by in-service teachers with varying degrees of teaching experience would be required. Furthermore, since previous studies on teachers' conceptions of atomic models had been conducted with national samples of teachers only, it was not yet clear to which extent their findings can be generalised on an international level. Indeed, the literature review suggested that additional research was warranted to narrow the existing research gap regarding teachers' conceptions. Specifically, to support the design of future professional development programmes for teachers, it was relevant to investigate which conceptions of atomic models are held by in-service teachers and how these conceptions influence their use of atomic models in the classroom. 


\section{Methodology}

\section{Research Goal}

To add another layer to the limited previous research on teachers' conceptions of atomic models, a large-scale international study was conducted with high school science teachers. The study was informed by the aforementioned findings and suggestions from studies, which had been mostly conducted with pre-service teachers from one country. Indeed, the rationale of the presented study was to further extend previous studies by conducting research with inservice teachers from different countries.

The study comprised two research phases: a pilot study and the main study. First, the teachers' conceptions study by Kiray (2016) was replicated with an international sample of in-service science teachers. As summarised above, their study was conducted with 142 Turkish pre-service teachers and showed that, when asked about their conception of an atom, half of the group drew Bohr's atomic model. However, due to their research setting, it is not clear to which extent these results could be generalised to in-service science teachers from different countries. Therefore, their study was replicated and based on the results of this pilot study a questionnaire with multiple choice questions was developed.

This questionnaire was then used during the main study with another international sample of in-service science teachers. In addition to investigating teachers' conceptions of atomic models, this questionnaire also collected data on teachers' knowledge about their students' conceptions of atomic models and teachers' use of atomic models in the classroom. In doing so, the study's research aim was focused both on investigating teachers' conceptions of atomic models and on documenting associated dimensions of their PCK, namely knowledge of learners and knowledge of instructional strategies. Specifically, the following research questions guided the research process:

(1) Which conceptions of atomic models held by in-service science teachers can be identified?

(2) What do in-service science teachers think are students' conceptions of atomic models?

(3) What are in-service science teachers' preferred atomic models for use in their classrooms?

\section{Study Setting}

The study was conducted at CERN, the European Laboratory for Particle Physics, that runs professional development programmes for in-service science teachers on a weekly basis. Every year about 1000 high school science teachers take part in these programmes, which focus on the topic of particle physics. Specifically, the programmes are divided into national programmes, in which groups of teachers from the same country take part, and international programmes, which are open to teachers from all around the world. The national programmes last for 3-5 days, while the international programmes last for two weeks. Hence, these professional development programmes offer a prime opportunity to conduct education research with in-service science teachers on an international level.

\section{Pilot Study}

As a first step, the teachers' conceptions study by Kiray (2016) was replicated with an international sample of 198 inservice science teachers from 12 countries. For this, the original research method was used. A blank sheet of paper was given to the teachers, with the task to draw their conceptions of an atom. Such a research approach is well-established in the field of science education, as drawings are commonly used to explore conceptions held by young students. Here, probably the most prominent example is the 'draw-a-scientist' test (Chambers, 1983; Finson, 2002), but studies can be found in various fields of science education research, such as technology education (Rennie \& Jarvis, 1995), environmental science education (Barraza, 1999), earth science education (Dove et al., 1999), and physics education (Neumann \& Hopf, 2013). Furthermore, drawings have also been used in studies investigating conceptions held by preservice teachers (Dikmenli, 2010; Lee \& Zeppelin, 2014; Markic et al., 2006). However, the method of drawings has its limitations. Indeed, students' drawings usually represent rather superficial knowledge structures, which limit deeper insights into their thoughts and reasoning (Neumann \& Hopf, 2013). Furthermore, it is quite likely that a person's ability to draw in general and the perceived easiness or difficulty in drawing certain objects influence the outcome of the drawing. Therefore, semi-structured one-on-one interviews were conducted with 24 randomly selected teachers to gather additional data on how to interpret their drawings and to discuss their conceptions of atomic models in detail. These interviews started with the request for the teacher to reproduce their drawing again the same way as they did before. Wide-angle cameras were used to record the interviews, which lasted about 4-5 minutes each and which were based on the following interview guide:

- Was it easy for you to make this drawing?

- Would you like to change something in the drawing? If so, what would you like to change?

- Does this drawing look like the image of an atom that you have in your head? If not, what would need to be changed?

- Do you use this representation of an atom also in your classroom? If not, can you please make a drawing of an atom that you would use for your teaching? 
The 198 drawings were analysed based on the coding procedure described by Kiray (2016), and the various atomic models were grouped into different categories accordingly. In total, six different categories of atomic models emerged from the analysis, which are detailed in the following section. The recordings of the semi-structured interviews were transcribed verbatim, and the transcripts were used to decide on the correct interpretation of a total of four ambiguous drawings. The analysis was peer-validated by two researchers in physics education, who carried out independent codings of all drawings. Their inter-coder reliability resulted in a Cohen's Kappa of $\kappa=0.975$, indicating an almost perfect agreement (Landis \& Koch, 1977).

\section{Main Study}

Based on the results of the pilot study, a multiple-choice questionnaire was developed for the main study. Here, the goal was to investigate teachers' conceptions of atomic models and to elicit information about their knowledge of learners and instructional strategies. Therefore, based on the study's research questions, the questionnaire consisted of the following three questions:

(1) When you think of an atom, what do you see?

(2) When your students think of an atom, what do they see?

(3) What is your favourite representation of an atom to use in the classroom?

The final phrasing of the three questions was iteratively developed based on the transcripts of the one-on-one interviews that were conducted during the pilot study. Many teachers suggested that they considered their conceptions to be mental models, which they can see 'in their head.' Hence, similar wording was used for the first two questions. Furthermore, several teachers stated that, depending on the context and their students' level, they use different atomic models in their classrooms. Therefore, the phrasing of the third question was adapted to only focus on their 'go-to' representation of an atom.

For each of the three questions, the six different categories of atomic models that emerged from the analysis of the pilot study were used as possible answers for teachers to choose one model from. Specifically, generic drawings of the six different atomic models were created (Figure 1), which represent blended versions of the majority of the 198 drawings collected during the pilot study. In addition, a free-draw option was included as a seventh option for teachers who found none of the six atomic models suitable to represent their conceptions.
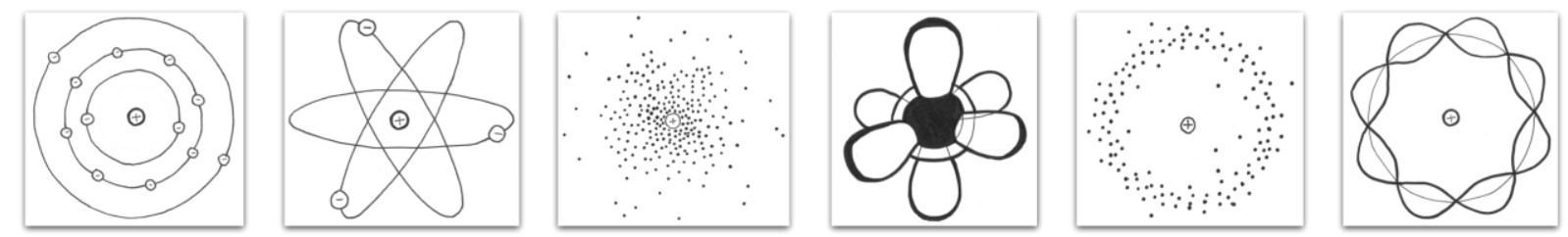

Figure 1. Generic drawings of the six atomic models that emerged from the analysis of the pilot study, representing, from left to right, the Bohr model, the Rutherford model, the probability model, the orbital model, the probability orbit model, and the wave model.

In total, 864 in-service science teachers from 55 countries took part in the main study and the English version of the questionnaire was used for all participants. However, for every non-English programme, native-speaking scientists were present during the data collection to provide translations in the native language of the teachers, if needed. As mentioned above, the study was conducted with teachers who took part in a professional development programme. Hence, to avoid any potential influences, the questionnaire was administered at the beginning of each teacher programme.

In addition to the questionnaire, semi-structured one-on-one interviews were conducted with 70 randomly selected teachers to discuss their conceptions of atoms and their use of atomic models in the classroom in detail. Here, wideangle cameras were again used to record the interviews, which were based on the following interview guide:

- Please describe your conception of an atom in your own words.

- What do you think are your students' conceptions of atoms?

- Which atomic models do you use in your classroom?

- Which factors influence your selection of the atomic models that you use in the classroom?

The interviews lasted about 3-4 minutes each, and they were partially transcribed to provide additional information for the interpretation of the data collected by the questionnaires. 
Sample

Combining both research phases, a total of 1062 in-service high school science teachers from 58 countries took part in this study. The geographical distribution is illustrated in Figure 2. The sample of teachers shows a well-balanced gender distribution (563 female teachers and 499 male teachers), a broad age range ( $\mathrm{M}=43$ years, SD = 10 years), and a wide distribution of their individual teaching experience $(M=16$ years, SD = 10 years). Indeed, the sample of the study can be considered as largely representative.

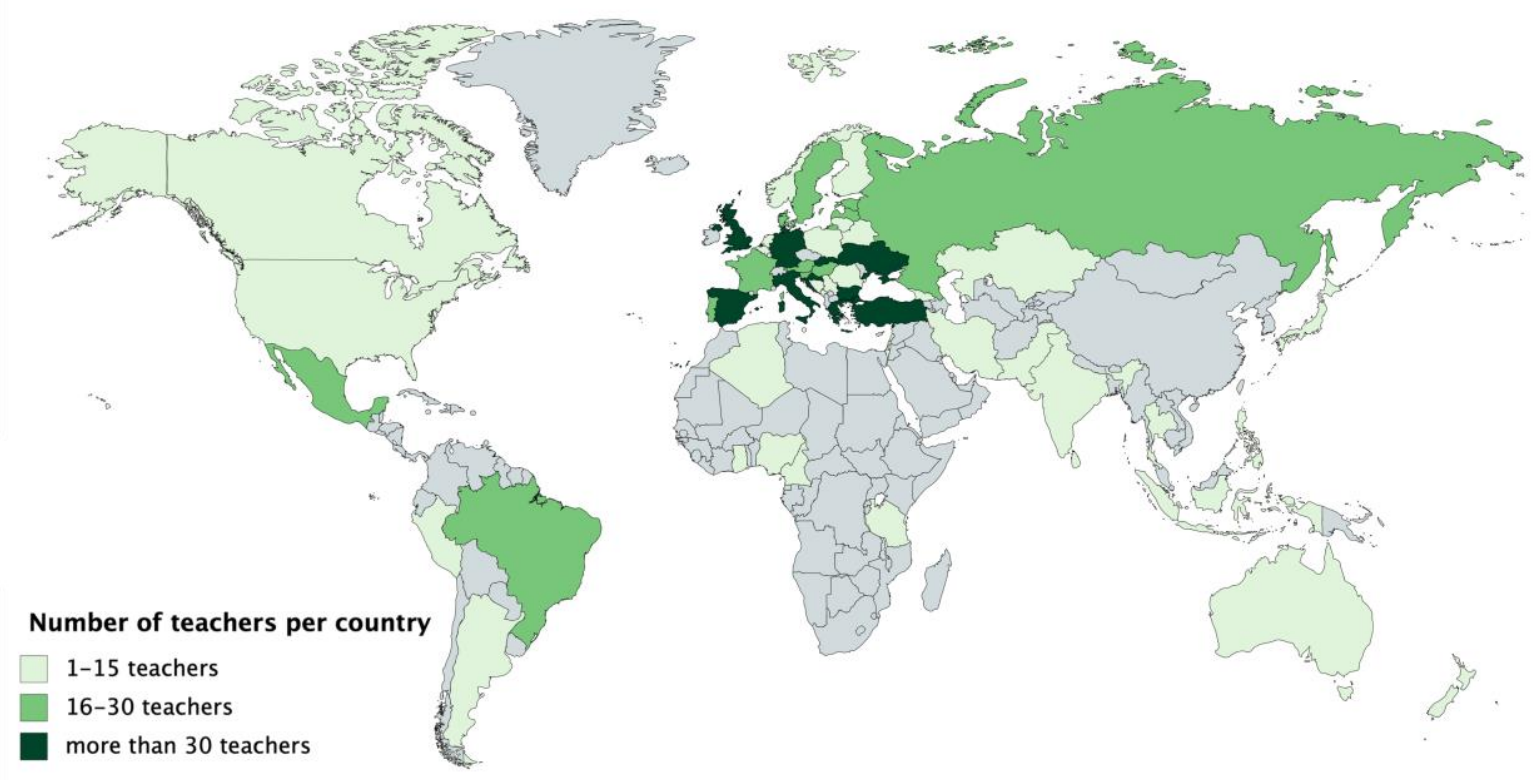

Figure 2. Geographical distribution of the 1062 in-service high school science teachers who took part in this study.

However, as the teachers took part in a professional development programme at a European particle physics laboratory when the study was conducted, the sample is self-selected, and a positive bias towards particle physics was documented. Specifically, when asked to rate their agreement with various statements about particle physics on a 6-point Likert-like scale, 93\% of the teachers agreed or strongly agreed with the statement that particle physics is fascinating. In contrast, $87 \%$ of the teachers disagreed or strongly disagreed with the statement that particle physics is boring. Thus, a cautionary note needs to be added when generalising from the findings of this study, which is also discussed in the limitations section.

\section{Results}

As mentioned above, six categories of atomic models emerged from the analysis of the 198 drawings collected during the pilot study. Specifically, the six categories cover two historical atomic models, namely the Bohr model and the Rutherford model, as well as four modern atomic models, namely the orbital model, the probability model, the probability orbit model, and the wave model (Figure 1). Here, the classification of the historical atomic models was taken from physics textbooks. In contrast, the categories for the modern atomic models stem from the works of Petri and Niedderer (1998) and of Müller and Wiesner (2002). Overall, the majority of teachers either drew the Bohr model (39\%), the probability model (28\%), or the Rutherford model $(20 \%)$. In contrast, only a few teachers drew the orbital model (11\%) and a negligible number of teachers drew the probability orbit model (1\%) or the wave model (1\%).

These findings are in line with the results reported by Kiray (2016), who also saw the majority of participants either draw the Bohr model (52\%) or the Rutherford model (13\%). However, it is worth noting that their analysis revealed a total of nine different categories of atomic models, of which only six were found during this pilot study. Specifically, in addition to the aforementioned categories and a category for mixed atomic models, they also listed categories for the so-called electronium model and the electronium orbit model, which stem from the quantum atomic teaching model proposed by Budde et al. (2002). Neither of these two models was drawn by teachers during the pilot study, nor were they mentioned during any of the one-on-one interviews. Indeed, it is quite likely that these atomic models were discussed as part of the pre-service teachers' university education, which would explain why they emerged in the analysis of their study.

However, the analysis of the one-on-one interviews, which were conducted during the pilot study, suggests that these drawings do not necessarily represent teachers' conceptions of atomic models. Indeed, during the interviews, almost all teachers stated that they chose to draw either the Bohr model or the Rutherford model as they were 'easy to draw.' Furthermore, when asked about their 'real' mental model of an atom, many of them revised their drawing to represent 
either the orbital model or the probability model. These revisions either suggest that the setting of the interview influenced the teachers to change their original drawing to a more modern atomic model or that their drawing, in fact, did not represent their conception of an atom. Here, the shortcomings of drawings as a research method became evident, and the need for a standardised test instrument arose. This led to the development of the multiple-choice questionnaire, which was used to collect data during the main study.

\section{Main Study}

The main study was conducted with 864 in-service teachers from 55 countries, who all filled out the multiple-choice questionnaire. Below, a descriptive overview of the teachers' responses to the three questions of the questionnaire is given, which are also summarised in Table 1. This is followed by a more detailed analysis of teachers' conceptions of atomic models with regard to their teaching experience and their use of atomic models in the classroom.

Table 1. Overview of the frequencies of teachers' responses to the three questions of the questionnaire.

\begin{tabular}{|c|c|c|c|c|c|c|}
\hline & $\begin{array}{l}\text { Bohr } \\
\text { model }\end{array}$ & $\begin{array}{l}\text { Rutherford } \\
\text { model }\end{array}$ & $\begin{array}{l}\text { Probability } \\
\text { model }\end{array}$ & $\begin{array}{l}\text { Orbital } \\
\text { model }\end{array}$ & $\begin{array}{l}\text { Probability } \\
\text { orbit } \\
\text { model }\end{array}$ & $\begin{array}{l}\text { Wave } \\
\text { model }\end{array}$ \\
\hline $\begin{array}{l}\text { 1) When you think of an atom, what } \\
\text { do you see? }\end{array}$ & $19 \%$ & $19 \%$ & $19 \%$ & $19 \%$ & $14 \%$ & $10 \%$ \\
\hline $\begin{array}{l}\text { 2) When your students think of an } \\
\text { atom, what do they see? }\end{array}$ & $52 \%$ & $38 \%$ & $3 \%$ & $3 \%$ & $3 \%$ & $1 \%$ \\
\hline $\begin{array}{l}\text { 3) What is your favourite } \\
\text { representation of an atom to use in } \\
\text { the classroom? }\end{array}$ & $52 \%$ & $22 \%$ & $6 \%$ & $7 \%$ & $7 \%$ & $6 \%$ \\
\hline
\end{tabular}

The first question of the questionnaire investigated teachers' conceptions of atomic models by asking them, 'When you think of an atom, what do you see?' Here, the teachers' responses showed an almost even distribution over the six atomic models, with 19\% each selecting either the Bohr model, the Rutherford model, the probability model, or the orbital model. In addition, $14 \%$ chose the probability orbit model and another $10 \%$ the wave model. It is worth noting that these six atomic models, which emerged from the analysis of the pilot study, turned out to be representative of the various teachers' conceptions. Specifically, no other atomic models were drawn or mentioned by teachers taking part in the main study.

The second question of the questionnaire focused on teachers' knowledge of learners by asking them, 'When your students think of an atom, what do they see?' Here, the teachers' responses revealed two clear favourites, namely the Bohr model (52\%) and the Rutherford model (38\%). In comparison, the remaining four modern atomic models were scarcely chosen, with $3 \%$ each for either the probability model, the orbital model, or the probability orbit model and only $1 \%$ for the wave model.

The third question of the questionnaire was directed at teachers' knowledge of instructional strategies by asking them, 'What is your favourite representation of an atom to use in the classroom?' Similar to the responses to the second question, the teachers' responses highlighted the two historical atomic models as preferred choices. Specifically, 52\% chose the Bohr model and another $22 \%$ the Rutherford model to be their 'go-to' representation of an atom in the classroom. The remaining four modern atomic models received significantly fewer nominations, with $7 \%$ each for either the orbital model or the probability orbit model, and $6 \%$ each for either the probability model or the wave model.

In conclusion, various conceptions of atomic models are held by in-service science teachers, which are almost evenly distributed over six different atomic models, without any one model standing out. Furthermore, the vast majority of inservice science teachers assume that their students' conceptions are centred on two historical atomic models, namely the Bohr model or the Rutherford model. Last, when it comes to the use of atomic models in the classroom, the majority of in-service science teachers prefer to use historical atomic models over modern atomic models. 


\section{Teachers' conceptions and teaching experience}

Next, a more detailed analysis of the teachers' responses to the three questions of the questionnaire was performed to reveal potential differences among the conceptions of atomic models held by teachers with varying degrees of teaching experience. Based on the broad distribution of teachers' individual teaching experience ( $\mathrm{M}=16$ years, SD = 10 years), the 864 teachers were grouped into seven bins (1-5 years, 6-10 years, 11-15 years, 16-20 years, 21-25 years, 26-30 years, $30+$ years), as shown in Table 2 .

Table 2. Distribution of the teaching experience of the 864 high school science teachers who took part in the main study.

\begin{tabular}{ccccccc}
\hline $\mathbf{1 - 5}$ years & $\mathbf{6 - 1 0}$ years & $\mathbf{1 1 - 1 5}$ years & $\mathbf{1 6 - 2 0}$ years & $\mathbf{2 1 - 2 5}$ years & $\mathbf{2 6 - 3 0}$ years & $\mathbf{3 0 +}$ years \\
\hline 144 teachers & 142 teachers & 148 teachers & 148 teachers & 106 teachers & 110 teachers & 66 teachers \\
\hline
\end{tabular}

Here, differences were found among teachers' responses to two of the three questions. Specifically, when looking at the first question, a decrease of historical atomic models in teachers' reported conceptions of atomic models can be identified (Figure 3). Indeed, 45\% of the early career teachers (1-5 years of teaching experience) chose either the Bohr model or the Rutherford model to represent their mental model of an atom. In comparison, only 36\% of experienced teachers (26-30 years of teaching experience) chose one of the two historical atomic models. However, for the veteran teachers of the sample (30+ years of teaching experience), the percentage went up to $42 \%$ again. Indeed, for both the early career teachers and the most experienced teachers of this sample, the reported frequencies of conceptions of historical atomic models are on a similar level.

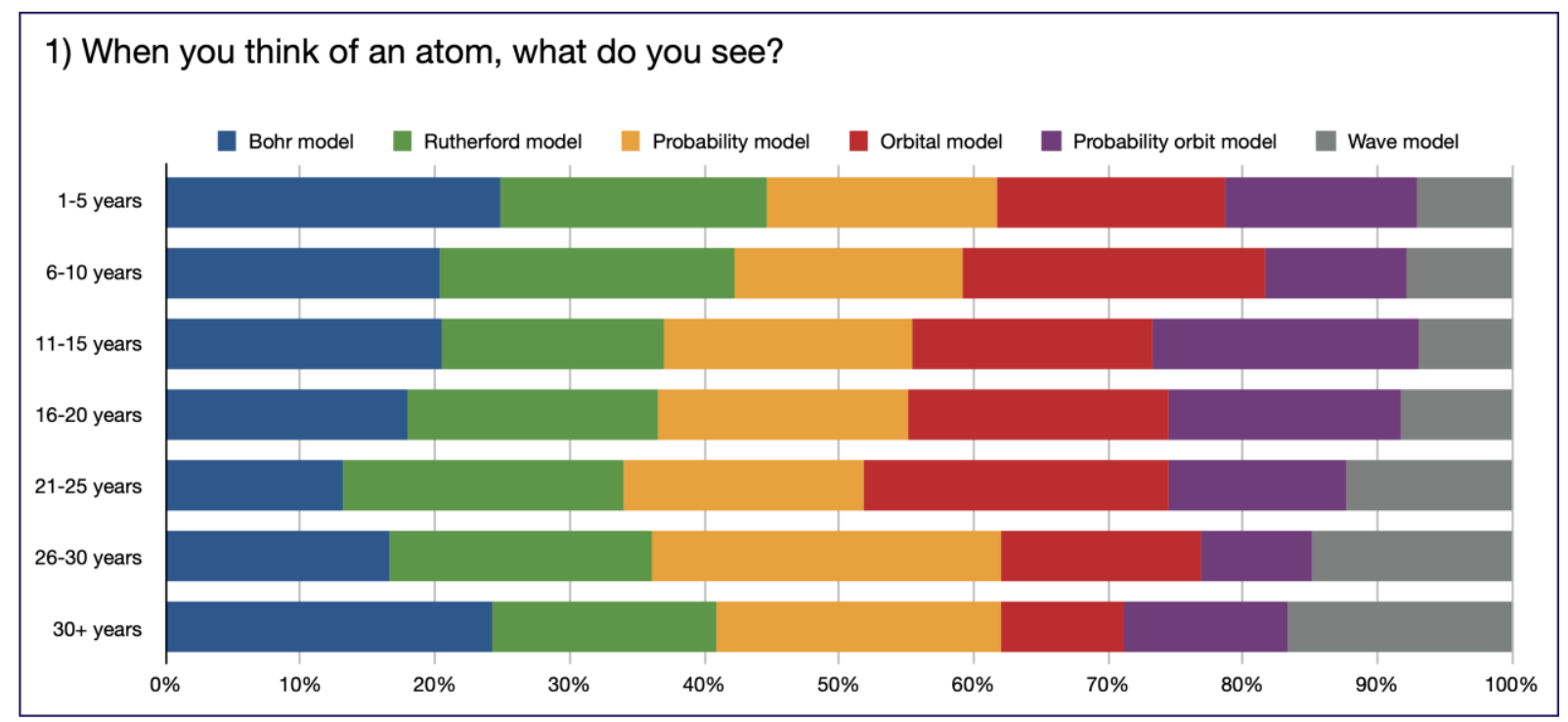

Figure 3. Teachers' responses to the first question of the questionnaire, grouped into seven bins of varying degrees of teaching experience.

An even more prominent effect was found with respect to teachers' responses to the third question, which investigated their 'go-to' atomic model to use in the classroom. Here, the data shows a highly significant negative correlation between teachers' experience and their reported use of historical atomic models in the classroom. Indeed, as illustrated in Figure 4, 85\% of the early career teachers (1-5 years of teaching experience) and 71\% of the experienced teachers (16-20 years of teaching experience) prefer to use either the Bohr model or the Rutherford model in their classrooms. In contrast, only $63 \%$ of the most experienced teachers of the sample (30+ years of teaching experience) chose a historical atomic model as their favourite educational representation of an atom. This highly significant correlation appeared both within the binned data, $\mathrm{r}(5)=-.98, \mathrm{p}<.001$, as well as within the primary data, $\mathrm{r}_{\mathrm{pb}}(862)=-.17, \mathrm{p}<.001$. According to the calculation suggested by Kornbrot (2014), the latter correlation coefficient translates to a small effect size of Cohen's $d=0.4$. 
3) What is your favourite representation of an atom to use in the classroom?

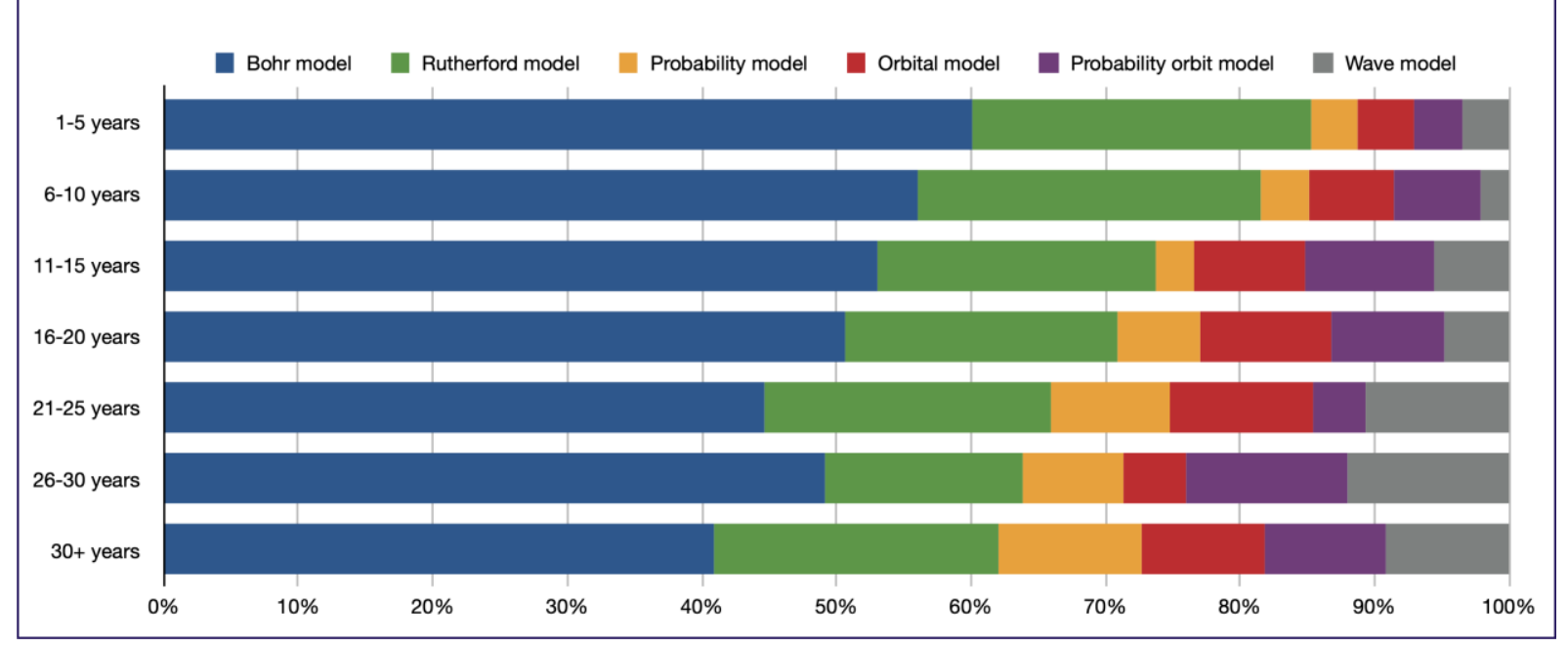

Figure 4. Teachers' responses to the third question of the questionnaire, grouped into seven bins of varying degrees of teaching experience.

In conclusion, teachers' conceptions of atomic models and their use of atomic models in the classroom are closely linked to their teaching experience. Specifically, the results suggest an influence of teachers' experience on their conception of atomic models, indicating a slight decrease of the conception of historical atomic models over time spent in the classroom. However, the results also show that early career teachers and veteran teachers hold similar conceptions of atomic models. Moreover, teachers' use of historical atomic models in the classroom is negatively correlated with their teaching experience. The findings highlight that the use of modern atomic models in the classroom is positively correlated with growing teaching experience.

\section{Teachers' conceptions and classroom practice}

Last, an analysis of the relationship between teachers' conceptions of atomic models and their use of atomic models in the classroom was performed. Specifically, the extent to which teachers' conceptions of atomic models and their perceptions of students' conceptions of atomic models influence the selection of their educational 'go-to' atomic model was investigated. Here, cross-tables were used to analyse the data collected by the questionnaires. For instance, Table 3 illustrates the combination of teachers' conceptions of atomic models and their use of atomic models in the classroom. The analysis shows a highly significant association between teachers' conceptions of atomic models and their favourite representation of an atom to use in the classroom $\left(\chi^{2}(25, \mathrm{~N}=864)=515.84, \mathrm{p}<.001\right)$, which according to Rea and Parker (2014) translates to a moderate effect size of Cramer's $V=.35, \mathrm{p}<.001$. When looking at the data presented in Table 3, two key findings stand out. First, the diagonal percentages indicate that $42 \%$ of the teachers use their conception of an atomic model to represent an atom in the classroom. Besides, the values in the first column of the table highlight that another $37 \%$ of the teachers use the Bohr model in their classroom, even if this is not their conception of an atomic model.

Table 3. Cross-table combining teachers' conceptions of atomic models and their use of atomic models in the classroom.

\begin{tabular}{lcccccc}
\hline \multirow{2}{*}{ 1) Teachers' conceptions } & \multicolumn{5}{c}{ 3) Favourite representation of an atom to use in the classroom } \\
\cline { 2 - 7 } & $\begin{array}{c}\text { Bohr } \\
\text { model }\end{array}$ & $\begin{array}{c}\text { Rutherford } \\
\text { model }\end{array}$ & $\begin{array}{c}\text { Probability } \\
\text { model }\end{array}$ & $\begin{array}{c}\text { Orbital } \\
\text { model }\end{array}$ & $\begin{array}{c}\text { Probability } \\
\text { orbit model }\end{array}$ & $\begin{array}{c}\text { Wave } \\
\text { model }\end{array}$ \\
\hline Bohr model & $\mathbf{1 5 \%}$ & $2 \%$ & $1 \%$ & $0 \%$ & $1 \%$ & $0 \%$ \\
Rutherford model & $\mathbf{8 \%}$ & $\mathbf{1 0 \%}$ & $0 \%$ & $0 \%$ & $1 \%$ & $0 \%$ \\
Probability model & $\mathbf{8 \%}$ & $3 \%$ & $\mathbf{5 \%}$ & $2 \%$ & $0 \%$ & $1 \%$ \\
Orbital model & $\mathbf{1 0 \%}$ & $3 \%$ & $0 \%$ & $\mathbf{5 \%}$ & $0 \%$ & $1 \%$ \\
Probability orbit model & $\mathbf{7 \%}$ & $2 \%$ & $0 \%$ & $0 \%$ & $\mathbf{4 \%}$ & $1 \%$ \\
Wave model & $\mathbf{4 \%}$ & $2 \%$ & $0 \%$ & $0 \%$ & $1 \%$ & $\mathbf{3 \%}$ \\
\hline
\end{tabular}

The same analysis was performed on teachers' assumed students' conceptions of atomic models and their use of atomic models in the classroom, which is illustrated in Table 4. Here, the analysis also shows a highly significant association $\left(\chi^{2}(25, \mathrm{~N}=864)=273.80, \mathrm{p}<.001\right)$, which translates to a moderate effect size of Cramer's $\mathrm{V}=.26, \mathrm{p}<.001$. When looking at the data presented in Table 4, one finds that $69 \%$ of the teachers who think that their students' conceptions are centred either on the Bohr model or the Rutherford model also use one of the two historical atomic models in their classroom. 
Table 4. Cross-table combining teachers' assumed students' conceptions of atomic models and their use of atomic models in the classroom.

\begin{tabular}{lcccccc}
\hline \multirow{2}{*}{ 2) Students' Conceptions } & \multicolumn{3}{c}{ 3) Favourite representation of an atom to use in the classroom } \\
\cline { 2 - 7 } & $\begin{array}{c}\text { Bohr } \\
\text { model }\end{array}$ & $\begin{array}{c}\text { Rutherford } \\
\text { model }\end{array}$ & $\begin{array}{c}\text { Probability } \\
\text { model }\end{array}$ & $\begin{array}{c}\text { Orbital } \\
\text { model }\end{array}$ & $\begin{array}{c}\text { Probability } \\
\text { orbit model }\end{array}$ & $\begin{array}{c}\text { Wave } \\
\text { model }\end{array}$ \\
\hline Bohr model & $\mathbf{3 4 \%}$ & $\mathbf{8 \%}$ & $2 \%$ & $3 \%$ & $3 \%$ & $2 \%$ \\
Rutherford model & $\mathbf{1 5 \%}$ & $\mathbf{1 2 \%}$ & $2 \%$ & $3 \%$ & $3 \%$ & $3 \%$ \\
Probability model & $1 \%$ & $0 \%$ & $2 \%$ & $0 \%$ & $0 \%$ & $0 \%$ \\
Orbital model & $1 \%$ & $1 \%$ & $0 \%$ & $1 \%$ & $0 \%$ & $0 \%$ \\
Probability orbit model & $1 \%$ & $1 \%$ & $0 \%$ & $0 \%$ & $1 \%$ & $0 \%$ \\
Wave model & $0 \%$ & $0 \%$ & $0 \%$ & $0 \%$ & $0 \%$ & $1 \%$ \\
\hline
\end{tabular}

However, it is worth noting that while the documented associations are highly significant, the analysis does not provide details about their directions. Specifically, based on the cross-tabulations, it is not possible to determine whether teachers' conceptions influence their instructional strategies, or if they are, in turn, influenced by teachers' classroom practice. Here, the analysis of the 70 one-on-one interviews provided additional information on how to interpret the direction of the associations. The majority of teachers stated that they do not consider their conception of an atomic model to be necessarily the most accurate one but to be the most appropriate model in an educational context, which they intend to transfer to their students. Hence, for this association, a direction from teachers' conceptions to their classroom practice can tentatively be inferred.

In contrast, regarding the association between teachers' assumed students' conceptions of atomic models and teachers' favourite representation of an atom to use in the classroom, the feedback from the teachers was less clear. Indeed, about half of the teachers stated that they use a certain atomic model in the classroom to connect to students' preexisting conceptions of atomic models. The other half of the teachers, however, reported that they perceived their students' conceptions of atomic models to mirror their educational 'go-to' atomic model, which is used in the classroom. Hence, these findings suggest that the relationship between teachers' assumed students' conceptions and their classroom practice is influenced in both directions.

In conclusion, teachers' conceptions of atomic models and their use of atomic models in the classroom are significantly associated. Indeed, the findings show that both teachers' conceptions of atomic models and teachers' knowledge of students' conceptions of atomic models influence their classroom practice. This corroborates the well-established notion that teachers' beliefs and conceptions play a crucial role in the educational process. However, additional research is required to provide a more detailed analysis of the directions of association between teachers' conceptions, students' conceptions, and teachers' classroom practice.

\section{Discussion}

This international study investigated conceptions of atomic models held by 1062 in-service science teachers from 58 countries. Specifically, the study was driven by three research questions, examining teachers' conceptions of atomic models, teachers' assumed students' conceptions of atomic models, and teachers' use of atomic models in the classroom. This unique study led to several promising results, which significantly advance the currently limited state of research on teachers' conceptions of atomic models. Below, the key findings concerning the study's research questions are discussed, and the strengths and limitations of the study are addressed. Last, general conclusions are drawn by highlighting implications for the field of science education research.

The first research question asked, 'Which conceptions of atomic models held by in-service science teachers can be identified?' Here, the results show that in fact, several conceptions of atomic models are held by in-service science teachers. Specifically, six different teachers' conceptions of atomic models were identified, namely the Bohr model and the Rutherford model as historical atomic models, and the probability model, the orbital model, the probability orbit model, and the wave model as modern atomic models. Indeed, the six atomic models cover all conceptions held by teachers, without any one model standing out. These results corroborate the outcome of the previously conducted study on Turkish pre-service teachers' conceptions of atomic models by Kiray (2016), which was successfully replicated with an international sample of in-service science teachers during the pilot phase of the presented research. Indeed, this international study not only expands the existing knowledge of teachers' conceptions, but it also answers to the critical call for more replication studies in the education sciences (Chhin et al., 2018; Good, 1992; Makel \& Plucker, 2014).

Furthermore, conducting the pilot study showed that using teachers' drawings as the primary source of data has methodological shortcomings, which was already documented for the interpretation of students' drawings (Neumann \& Hopf, 2013). It is in this sense that only the documented teachers' conceptions that were collected with the developed multiple-choice questionnaire during the main study can be considered to be representative on a general level. 
Moreover, the data shows a prominent connection between teachers' conceptions of atomic models and their teaching experience. Specifically, when distinguishing between historical atomic models and modern atomic models, the findings indicate a slight decrease in teachers' conceptions of historical atomic models over time spent in the classroom. This tentatively supports the hypothesis by Hashweh (2005) that teachers' conceptions develop through repeatedly teaching a particular topic. However, the results also show that early career teachers (1-5 years of teaching experience) and veteran teachers (30+ years of teaching experience) hold similar conceptions of atomic models. Here, one possible explanation lies in the fact that today's veteran teachers started their teaching career already in the 1980s, but the educational reconstruction of modern atomic models, which led to the discussion among education researchers how best to introduce them in the classroom only arose at the end of the 1990s (Fischler \& Lichtfeldt, 1992; Justi \& Gilbert, 2000; Kalkanis et al., 2003). Hence, it is possible to conclude that conceptions of teachers who have already spent more than 30 years in the classroom are less likely to be influenced by current findings from education research.

The second research question asked, 'What do in-service science teachers think are students' conceptions of atomic models?' Here, the results show a very clear picture, with $90 \%$ of all teachers choosing either the Bohr model or the Rutherford model as their students' conception of an atomic model. Indeed, the vast majority of teachers considers their students' conceptions to be centred on one of the two historical atomic models. In this regard, the study provides useful information on one essential dimension of in-service science teachers' PCK, namely their knowledge of learners (Magnusson et al., 1999), which is an underrepresented area in the research literature (Abell, 2007).

Furthermore, two possible explanations for the reasoning of teachers to choose a specific atomic model as the assumed conception of their students were found. Specifically, many teachers consider their students' conceptions of atomic models to be existing prior to their education. Various statements by teachers were documented, mentioning that they see both the Bohr model and the Rutherford model to be commonly used to represent atoms in their students' daily lives. Here the most prominent example given by teachers was the popular sitcom 'The Big Bang Theory,' which uses animations of the Rutherford model to transition between scenes. However, many teachers also stated that they chose a certain atomic model to represent their students' conception as it is the most frequently used atomic model in their teaching. Hence, while both possible explanations have merit, it is worth noting that additional research is required to provide a more detailed analysis of teachers' knowledge of students' conceptions of atomic models.

The third research question asked, 'What are in-service science teachers' preferred atomic models for use in their classrooms?' Here, the results show a very clear picture with $74 \%$ of the teachers indicating that they use either the Bohr model or the Rutherford model as their 'go-to' atomic model. In contrast, the four modern atomic models received significantly fewer nominations, hinting at the fact that their transfer into the classroom is hindered. This notion is underlined by statements made by several teachers from different countries, who mentioned that they have to use the Bohr model to comply with their respective curricula or to appropriately align their instructional strategies with the illustrations used in their textbooks.

Although the vast majority of teachers uses one of the two historical atomic models in their teaching, a highly significant correlation between teachers' experience and their use of modern atomic models was documented. Indeed, only $15 \%$ of the early-career teachers (1-5 years of teaching experience), but $36 \%$ of the experienced teachers (26-30 years of teaching experience) and $37 \%$ of the most experienced teachers (30+ years of teaching experience) selected one of the four modern atomic models as their 'go-to' atomic model in the classroom. These results support previous findings that experienced teachers tend to have a bigger repertoire of instructional strategies and teaching approaches (Caleon et al., 2018). Furthermore, the findings show that while conceptions of veteran teachers are not influenced by recent findings of education research, their instructional strategies certainly are.

Last, highly significant associations of teachers' conceptions of atomic models and their assumed students' conceptions of atomic models with their use of atomic models in the classroom were documented. Specifically, the results show that many teachers prefer to use their conception of an atomic model to represent an atom in the classroom and that the majority of teachers take their students' conceptions of atomic models into account. However, the data does not provide a more detailed insight into the specific directions of these associations. For instance, while the findings indicate that teachers' conceptions significantly influence their classroom practice, no clear verdict can be made about the influence of teachers' classroom practice on their conceptions. Indeed, additional research is required to appropriately investigate the directions of association between teachers' conceptions, students' conceptions, and teachers' classroom practice.

\section{Limitations}

This international study documented the conceptions of atomic models held by 1062 in-service high school science teachers from 58 countries. Indeed, one strength of the study lies in the sample of teachers who took part both in the pilot study and in the main study of the presented research. Specifically, this study documented in-service science teachers' conceptions of atomic models on an unprecedented level. In doing so, a significant advancement of the currently limited state of research on teachers' conceptions was achieved. Moreover, by replicating the previously conducted study on pre-service teachers' conceptions of atomic models by Kiray (2016) during the pilot phase of the presented study, an additional layer was added to the field of physics education research. Indeed, the successful 
replication and further development of the original study showcase the positive effects of underpinning new research with previously documented findings and advocate for more replication studies in the education sciences.

Due to its international nature, however, the study is subject to limitations, which need to be addressed. First, the fact that the teachers took part in a professional development programme at CERN when the study was conducted limits the generalisability of the results. While the sample of teachers was truly international, it was also self-selected, and a positive bias towards the topic of particle physics was documented among the teachers. Thus, a cautionary note needs to be added when generalising from the findings of this study. However, the fact that no atomic model stood out among the various documented teachers' conceptions suggests that the influence of the bias is of minor importance.

Second, to collect data from teachers of different nationalities, the research instrument needed to include only a minimal amount of text to allow for a trouble-free data collection. This resulted in the development of a multiple-choice questionnaire with three questions. As mentioned above, the phrasing of the three questions was iteratively developed by taking the feedback of teachers, which was provided during the one-on-one interviews of the pilot study, into account. Indeed, the formulations of the second and third question of the questionnaire were kept on a comprehensive level. Specifically, the second question asked about students' conceptions of atomic models in general, without specifying a particular age range of the students. Along the same lines, question three asked for teachers' favourite atomic model to use in the classroom, without detailing a specific age range or instructional strategy. The reasoning behind both phrasings was to elicit comparable data of teachers from many countries, without the need for individual translations of the questionnaire for every language group. Thus, only general conclusions can be drawn from the results, and additional research is required to provide more detailed insights into the specifics of teachers' conceptions of atomic models.

Third, the generic drawings of the six atomic models, which were used as possible answers in the questionnaire, deserve consideration. The purpose of the drawings was to feature key aspects of the six different atomic models to distinguish them from each other. Therefore, their design was based on standard illustrations found in textbooks and on illustrations published by physics education researchers (Müller \& Wiesner, 2002; Petri \& Niedderer, 1998). To avoid obstructive details, the drawings did not exhibit a graphical substructure, such as protons and neutrons, and no labels were added. Here, no difficulties regarding the discernment of the six different atomic models were documented during this study. However, it is worth noting that the generic character of the drawings could potentially confuse inexperienced teachers or students.

\section{Recommendations}

Overall, the study led to promising results. Indeed, for the first time, conceptions of atomic models held by in-service high school science teachers were documented on an international level. Here, the results show that various conceptions of atomic models are common among teachers, without any one atomic model standing out. Furthermore, several additional promising findings were documented, which provide valuable insights both for science education research and science teacher education.

From a science education research perspective, this study adds another contribution to the discussion as to how the particulate nature of matter is introduced in the classroom. Specifically, there is quite some discrepancy in the literature over whether teachers should use historical atomic models in the classroom (Justi \& Gilbert, 2000; McKagan et al., 2008) or if they should instead focus on the current scientific understanding by using modern atomic models (Budde et al., 2002; Fischler \& Lichtfeldt, 1992; Kalkanis et al., 2003; Müller \& Wiesner, 2002). Here, the findings of the study illustrate that modern atomic models play only a minor role in high school science teachers' practice. Indeed, the majority of in-service science teachers indicated that they prefer to use historical atomic models over modern atomic models in the classroom. Hence, significant efforts from curriculum designers and education policymakers would be required to facilitate a transfer towards a more current scientific understanding of atomic models in the classroom.

From a science teacher education perspective, the following results deserve to be considered. First, the fact that teachers' conceptions significantly influence teachers' classroom practice highlights the need for high-quality teacher education and ongoing professional development programmes to focus on teachers' conceptual understanding. Moreover, a similar association was found between teachers' assumed students' conceptions of atomic models and their classroom practice. Hence, the findings suggest that for such a professional development programme to be effective the focus also needs to be placed on enhancing teachers' knowledge of learners as an essential dimension of their PCK (Park \& Oliver, 2008). This supports the previously documented notion that focusing on students' domainspecific processes of learning and understanding is listed among the key features of effective professional development programmes (Lipowsky \& Rzejak, 2015). Last, the finding that teachers' conceptions of atomic models develop and improve over time spent in the classroom illustrates the vital role experienced teachers play in an educational environment. Indeed, the influence of recommendations from trusted colleagues has already been characterised to be vital for teachers' development of their PCK (Bindernagel \& Eilks, 2009; Schneider \& Plasman, 2011). Hence, it can be concluded that professional development programmes should bring together teachers with varying degrees of teaching experience and provide them with clear opportunities to individually and collectively reflect on their teaching practice. 


\section{References}

Abell, S. K. (2007). Research on science teacher knowledge. In S. K. Abell \& N. G. Lederman (Eds.), Handbook of research on science education (pp. 1105-1149). Lawrence Erlbaum Associates.

Adbo, K., \& Taber, K. S. (2009). Learners' mental models of the particle nature of matter: A study of 16-year-old Swedish science students. International Journal of Science Education, 31(6), 757-786.

Anderson, R. D., \& Helms, J. V. (2001). The ideal of standards and the reality of schools: Needed research. Journal of Research in Science Teaching, 38(1), 3-16.

Barnes, N., Fives, H., \& Dacey, C. M. (2017). U.S. teachers' conceptions of the purposes of assessment. Teaching and Teacher Education, 65, 107-116. https://doi.org/10.1016/j.tate.2017.02.017

Barraza, L. (1999). Children's drawings about the environment. Environmental Education Research, 5(1), 49-66.

Bergqvist, A., Drechsler, M., \& Chang Rundgren, S.-N. (2016). Upper secondary teachers' knowledge for teaching chemical bonding models. International Journal of Science Education, 38(2), 298-318.

Bindernagel, J. A., \& Eilks, I. (2009). Evaluating roadmaps to portray and develop chemistry teachers' PCK about curricular structures concerning sub-microscopic models. Chemistry Education Research and Practice, 10(2), 77-85.

Budde, M., Niedderer, H., Scott, P., \& Leach, J. (2002). 'Electronium': A quantum atomic teaching model. Physics Education, 37(3), 197-203.

Caleon, I. S., Tan, Y. S. M., \& Cho, Y. H. (2018). Does teaching experience matter? The beliefs and practices of beginning and experienced physics teachers. Research in Science Education, 48(1), 117-149.

Chambers, D. W. (1983). Stereotypic images of the scientist: The draw-a-scientist test. Science Education, 67(2), 255265.

Chhin, C. S., Taylor, K. A., \& Wei, W. S. (2018). Supporting a culture of replication: An examination of education and special education research grants funded by the Institute of Education Sciences. Educational Researcher, 47(9), 594605.

Dikmenli, M. (2010). Misconceptions of cell division held by student teachers in biology: A drawing analysis. Scientific Research and Essays, 5(2), 235-247.

Dove, J. E., Everett, L. A., \& Preece, P. F. W. (1999). Exploring a hydrological concept through children's drawings. International Journal of Science Education, 21(5), 485-497.

Duit, R., \& Treagust, D. F. (2003). Conceptual change: A powerful framework for improving science teaching and learning. International Journal of Science Education, 25(6), 671-688.

Eilks, I. (2015). On the transformation of research on teaching and learning about the sub-micro world in chemistry education into feasable classroom practice. LUMAT: International Journal on Math, Science and Technology Education, 3(3), 269-284.

Feynman, R. P., Leighton, R. B., \& Sands, M. (2010). The Feynman lectures on physics. The new millennium edition. Volume I: mainly mechanics, radiation, and heat. Basic Books.

Finson, K. D. (2002). Drawing a scientist: What we do and do not know after fifty years of drawings. School Science and Mathematics, 102(7), 335-345.

Fischler, H., \& Lichtfeldt, M. (1992). Modern physics and students' conceptions. International Journal of Science Education, 14(2), 181-190.

Fives, H., \& Buehl, M. M. (2012). Spring cleaning for the "messy" construct of teachers' beliefs: What are they? Which have been examined? What can they tell us? In K. R. Harris, S. Graham, \& T. Urban (Eds.), APA Educational psychology handbook: Vol. 2. Individual differences and cultural and contextual factors (pp. 471-499). APA.

Gilbert, J. K. (2004). Models and modelling: Routes to more authentic science education. International Journal of Science and Mathematics Education, 2(2), 115-130.

Gómez, E. J., Benarroch, A., \& Marín, N. (2006). Evaluation of the degree of coherence found in students' conceptions concerning the particulate nature of matter. Journal of Research in Science Teaching, 43(6), 577-598.

Good, R. (1992). The importance of replication studies. Journal of Research in Science Teaching, 29 (3), 209.

Griffiths, A. K., \& Preston, K. R. (1992). Grade-12 students' misconceptions relating to fundamental characteristics of atoms and molecules. Journal of Research in Science Teaching, 29(6), 611-628. 
Gunnarsson, R., Hellquist, B., Strömdahl, H., \& Zelic, D. (2018). Secondary school science teachers' arguments for the particulate nature of matter. Journal of Research in Science Teaching, 55(4), 503-525.

Harrison, A. G., \& Treagust, D. F. (1996). Secondary students' mental models of atoms and molecules: Implications for teaching chemistry. Science Education, 80(5), 509-534.

Harrison, A. G., \& Treagust, D. F. (2002). The particulate nature of matter: Challenges in understanding the submicroscopic world. In J. K. Gilbert, O. De Jong, R. Justi, D. F. Treagust, \& J. H. Van Driel (Eds.), Chemical education: Towards research-based practice (pp. 189-212). Kluwer Academic Publishers.

Hashweh, M. Z. (2005). Teacher pedagogical constructions: A reconfiguration of pedagogical content knowledge. Teachers and Teaching: Theory and Practice, 11(3), 273-292.

Hestenes, D. (1987). Toward a modeling theory of physics instruction. American Journal of Physics, 55(5), 440-454.

Jong, O. D., Van Driel, J. H., \& Verloop, N. (2005). Preservice teachers' pedagogical content knowledge of using particle models in teaching chemistry. Journal of Research in Science Teaching, 42(8), 947-964.

Justi, R., \& Gilbert, J. (2000). History and philosophy of science through models: Some challenges in the case of 'the atom'. International Journal of Science Education, 22(9), 993-1009.

Kalkanis, G., Hadzidaki, P., \& Stavrou, D. (2003). An instructional model for a radical conceptual change towards quantum mechanics concepts. Science Education, 87(2), 257-280.

Kiray, S. A. (2016). The pre-service science teachers' mental models for concept of atoms and learning difficulties. International Journal of Education in Mathematics, Science and Technology, 4(2), 147-162.

Kornbrot, D. (2014). Point biserial correlation. In N. Balakrishnan, T. Colton, B. Everitt, W. Piegorsch, F. Ruggeri, \& J. L. Teugels (Eds.), Wiley StatsRef: Statistics reference online. Wiley.

Landis, J. R., \& Koch, G. G., (1977). The measurement of observer agreement for categorical data. Biometric, 33(1), 159174.

Lee, J. -E., \& Zeppelin, M. (2014). Using drawings to bridge the transition from student to future teacher of mathematics. International Electronic Journal of Elementary Education, 6(2), 333-346.

Lipowsky, F., \& Rzejak, D. (2015). Key features of effective professional development programmes for teachers. Ricercazione, 7(2), 27-51.

Magnusson, S., Krajcik, J., \& Borko, H. (1999). Nature, sources and development of pedagogical content knowledge for science teaching. In J. Gess-Newsome \& N. G. Lederman (Eds.), Examining pedagogical content knowledge: The construct and its implications for science education (pp. 95-132). Kluwer.

Makel, M. C., \& Plucker, J. A. (2014). Facts are more important than novelty: Replication in the education sciences. Educational Researcher, 43(6), 304-316.

Margel, H., Eylon, B.-S., \& Scherz, Z. (2008). A longitudinal study of junior high school students' conceptions of the structure of materials. Journal of Research in Science Teaching, 45(1), 132-152.

Markic, S., Valanides, N., \& Eilks, I (2006). Freshman science student teachers' beliefs on science teaching and learning A mixed methods study. In I. Eilks \& B. Ralle (Eds.), Towards research-based science teacher education (pp. 29-40). Shaker.

McKagan, S. B., Perkins, K. K., \& Wieman, C. E. (2008). Why we should teach the Bohr model and how to teach it effectively. Physical Review Special Topics - Physics Education Research, 4(1), 010103.

Müller, R., \& Wiesner, H. (2002). Teaching quantum mechanics on an introductory level. American Journal of Physics, 70(3), 200-209.

Neumann, S., \& Hopf, M. (2013). Children's drawings about "radiation" - before and after Fukushima. Research in Science Education, 43(4), 1535-1549.

Pajares, M. F. (1992). Teachers' beliefs and educational research: Cleaning up a messy construct. Review of Educational Research, 62(3), 307-332.

Park, E. J., \& Light, G. (2009). Identifying atomic structure as a threshold concept: Student mental models and troublesomeness. International Journal of Science Education, 31(2), 233-258.

Park, S., \& Oliver, J. S. (2008). Revisiting the conceptualisation of pedagogical content knowledge (PCK): PCK as a conceptual tool to understand teachers as professionals. Research in Science Education, 38(3), 261-284.

Petri, J., \& Niedderer, H. (1998). A learning pathway in high-school level quantum atomic physics. International Journal of Science Education, 20(9), 1075-1088. 
Rea, L. M., \& Parker, R. A. (2014). Designing and conducting survey research. A comprehensive guide. Jossey-Bass.

Rennie, L. J., \& Jarvis, T. (1995). Children's choice of drawings to communicate their ideas about technology. Research in Science Education, 25(3), 239-252.

Rodríguez, M. A., \& Niaz, M. (2004). A reconstruction of structure of the atom and its implications for general physics textbooks: A history and philosophy of science perspective. Journal of Science Education and Technology, 13(3), 409424.

Samarapungavan, A., Bryan, L., \& Wills, J. (2017). Second graders' emerging particle models of matter in the context of learning through model-based inquiry. Journal of Research in Science Teaching, 54(8), 988-1023.

Schneider, R. M., \& Plasman, K. (2011). Science teacher learning progressions: A review of science teachers' pedagogical content knowledge development. Review of Educational Research, 81(4), 530-565.

Snir, J., Smith, C. L., \& Raz, G. (2003). Linking phenomena with competing underlying models: A software tool for introducing students to the particulate model of matter. Science Education, 87, 794-830.

Thompson, A. G. (1992). Teachers' beliefs and conceptions: A synthesis of the research. In D. A. Grouws (Ed.), Handbook of research on mathematics teaching and learning (pp. 127-146). National Council of Teachers of Mathematics.

Thomson, J. J. (1897). Cathode rays. The London, Edinburgh, and Dublin Philosophical Magazine and Journal of Science, 44, 293-316.

Treagust, D. F., Chandrasegaran, A. L., Crowley, J., Yung, B. H. W., Cheong, I. P. A., \& Othman, J. (2010). Evaluating students' understanding of kinetic particle theory concepts relating to the states of matter, changes of state and diffusion: A cross-national study. International Journal of Science and Mathematics Education, 8(1), 141-164.

Vikström, A. (2014). What makes the difference? Teachers explore what must be taught and what must be learned in order to understand the particulate character of matter. Journal of Science Teacher Education, 25, 709-727.

Wiener, G. J., Schmeling, S. M., \& Hopf, M. (2018). The technique of probing acceptance as a tool for teachers' professional development: A PCK study. Journal of Research in Science Teaching, 55(6), 849-875.

Wiser, M., \& Smith, C. L. (2008). Learning and teaching about matter in grades K-8: When should the atomic-molecular theory be introduced? In S. Vosniadou (Ed.), International handbook of research on conceptual change (pp. 205-239). Routledge. 